\title{
Article
}

\section{The Procoagulant Effect of COVID-19 on the Thrombotic Risk of Patients with Hip Fractures Due to Enhanced Clot Strength and Fibrinolysis Shutdown}

\author{
Andreas G. Tsantes ${ }^{1, *,+}+\mathbb{C}$, Dimitrios V. Papadopoulos ${ }^{2,+}{ }^{+}$Ioannis G. Trikoupis ${ }^{3}$, Stavros Goumenos ${ }^{3}$, \\ Daniele Piovani ${ }^{4,5}$, Konstantina A. Tsante ${ }^{1}$, Andreas F. Mavrogenis ${ }^{3}{ }^{\mathbb{D}}$, Aristeidis G. Vaiopoulos ${ }^{1}$, \\ Panagiotis Koulouvaris ${ }^{3}$, Georgios K. Nikolopoulos ${ }^{6}$, Panayiotis J. Papagelopoulos ${ }^{3}$, Stefanos Bonovas ${ }^{4,5, *}$ (D) \\ and Argirios E. Tsantes ${ }^{1}$
}

1 Laboratory of Haematology and Blood Bank Unit, "Attiko" Hospital, School of Medicine, National and Kapodistrian University of Athens, 12462 Athens, Greece; ktsante@yahoo.com (K.A.T.); avaiopoulos@gmail.com (A.G.V.); atsantes@yahoo.com (A.E.T.)

2 Department of Orthopaedic Surgery, University of Pittsburgh, Pittsburgh, PA 15237, USA; di_papadopoulos@yahoo.gr

3 First Department of Orthopaedics, National and Kapodistrian, School of Medicine, University of Athens, 12462 Athens, Greece; gtrikoupis@hotmail.com (I.G.T.); stgoumenos@gmail.com (S.G.); afm@otenet.gr (A.F.M.); info@drkoulouvaris.gr (P.K.); pjporthopedic@gmail.com (P.J.P.)

check for updates

Citation: Tsantes, A.G.;

Papadopoulos, D.V.; Trikoupis, I.G.; Goumenos, S.; Piovani, D.; Tsante,

K.A.; Mavrogenis, A.F.; Vaiopoulos, A.G.; Koulouvaris, P.; Nikolopoulos, G.K.; et al. The Procoagulant Effect of COVID-19 on the Thrombotic Risk of Patients with Hip Fractures Due to Enhanced Clot Strength and Fibrinolysis Shutdown. J. Clin. Med. 2021, 10, 3397. https://doi.org/ $10.3390 /$ jcm10153397

Academic Editor: Victor Valderrabano

Received: 8 July 2021

Accepted: 29 July 2021

Published: 30 July 2021

Publisher's Note: MDPI stays neutral with regard to jurisdictional claims in published maps and institutional affiliations.

Copyright: (c) 2021 by the authors. Licensee MDPI, Basel, Switzerland. This article is an open access article distributed under the terms and conditions of the Creative Commons Attribution (CC BY) license (https:/ / creativecommons.org/licenses/by/ $4.0 /)$.
4 Department of Biomedical Sciences, Humanitas University, Pieve Emanuele, 20090 Milan, Italy; dpiovani@hotmail.com

5 IRCCS Humanitas Research Hospital, Rozzano, 20089 Milan, Italy

6 Department of Epidemiology and Public Health, Medical School, University of Cyprus, Nicosia 1678, Cyprus; gnikolopoulos@gmail.com

* Correspondence: andreas.tsantes@yahoo.com (A.G.T.); sbonovas@gmail.com (S.B.); Tel.: +30-6984533617 (A.G.T.)

+ The first two authors have equal contributions.

Abstract: Introduction: Coronavirus disease 2019 (COVID-19) in patients with hip fractures is associated with increased incidence of venous thromboembolism (VTE). The purpose of this study was to evaluate the hemostatic alterations of COVID-19 that are associated with a higher thrombotic risk using rotational thromboelastometry (ROTEM). Methods: A retrospective observational study was performed including 20 COVID-19 patients with hip fractures. To compare the coagulopathy of patients with mild COVID-19 and hip fractures with the coagulopathy associated with each of these two conditions separately, we used two previously recruited groups of patients; 198 hip fracture patients without COVID-19 and 21 COVID-19 patients without hip fractures. The demographics, clinical parameters, conventional coagulation parameters and ROTEM findings of the three groups were analyzed and compared. Results: COVID-19 hip fracture patients had higher amplitude of clot firmness at $10 \mathrm{~min}(p<0.001)$, higher alpha angle $(p<0.001)$, higher lysis index at $60 \mathrm{~min}$ $(p<0.001)$, and shorter clot formation time $(p<0.001)$ than non-COVID-19 hip fracture patients, indicating increased clot strength and impaired fibrinolysis due to COVID-19. The value of lysis index at $60 \mathrm{~min}$ (99\%) in COVID-19 patients with hip fractures was consistent with fibrinolysis shut down. Multivariable linear regression analysis further confirmed that COVID-19 resulted in increased amplitude of clot firmness at $10 \mathrm{~min}(p<0.001)$, increased maximum clot firmness $(p<0.001)$, increased lysis index at $60 \mathrm{~min}(p<0.001)$ and increased alpha angle $(p<0.001)$, but significantly shortened clot formation time $(p<0.001)$. Discussion: The higher thrombotic risk in COVID-19 patients with hip fractures is characterized by increased clot strength and fibrinolysis shutdown, as shown by ROTEM findings. Further prospective studies are warranted to evaluate the need for modification of thromboprophylaxis to balance the hemostatic derangements of COVID-19 patients with hip fractures.

Keywords: COVID-19; hip fractures; coagulopathy; thrombotic risk; fibrinolysis shutdown 


\section{Introduction}

The COVID-19 pandemic has transformed trauma care services, with a paucity of elective surgeries compensating for the limited operating capacity. Although there was a significant reduction in major orthopedic trauma due to reduced population activity, the incidence of fragility fractures such as hip fractures remained unchanged [1-4]. These injuries are common in elderly people, a population highly susceptible to COVID-19. Although the exact impact of COVID-19 on the morbidity and mortality of these patients is not clear, it appears that the additive effect of COVID-19 leads to poor outcomes and a low survival rate [5]. Both conditions have a high risk for certain adverse events such as venous thromboembolism, thus the overall risk for such complications is significantly increased.

Although with the advent of modern thromboprophylaxis the incidence of venous thromboembolism after hip fractures has been substantially decreased, the rate is still relatively high [6]. Several causes contribute to the thrombotic risk of hip fractures including endothelial damage and immobilization, while enhanced thrombin generation due to trauma-induced coagulopathy has also been hypothesized [7,8]. Numerous studies have also shown that COVID-19 results in a prothrombotic state with devastating clinical implications due to arterial and venous thromboembolic events [9-12]. There is a large body of emerging evidence regarding the pathophysiologic mechanisms involved in this prothrombotic state. Viral infection-associated inflammation and endothelial dysfunction have been theorized as the leading causes of prothrombotic state, while impaired fibrinolysis has been identified as an important mechanism for COVID-19 associated coagulopathy $[9,10]$.

Laboratory evaluation of coagulation is valuable since changes in the hemostatic profile of these patients have been associated with certain complications and patients' prognosis. Although d-dimers and fibrinogen levels are commonly elevated in patients with COVID-19, these laboratory findings cannot reliably identify patients at high risk for thromboembolism. Viscoelastic methods such as rotational thromboelastometry (ROTEM) provide a detailed insight into clot dynamics. Due to their advantageous properties, these methods have the potential to detect the level of hypercoagulability associated with increased thromboembolic risk [8]. Broad evidence exists regarding the use of viscoelastic methods to predict thromboembolic rates $[13,14]$.

The purpose of this pilot study was to evaluate the hemostatic profile of patients with hip fractures and concomitant COVID-19 using rotational thromboelastometry, and to assess the impact of COVID-19 infection on the procoagulant state of patients with hip fractures.

\section{Material and Methods}

A pilot retrospective observational study was performed from August 2020 to February 2021 at the Attikon University Hospital of Athens. COVID-19 patients with hip fractures were considered eligible for the study, while patients with congenital or acquired coagulopathies were excluded. All patients received prophylactic doses of low molecular weight heparin (LMWH). The extrinsically activated ROTEM test (EXTEM) was performed in all patients (ROTEM analyzer; Tem Innovations $\mathrm{GmbH}$, Munich, Germany), as previously described [15]. The following EXTEM parameters were recorded: clotting time (CT, seconds); clot formation time (CFT, seconds); amplitude recorded at $10 \mathrm{~min}$ (A10, $\mathrm{mm})$; a angle ( $\mathrm{a}^{\circ}$ ); maximum clot firmness (MCF, $\mathrm{mm}$ ) and lysis index at $60 \mathrm{~min}$ (LI60, \%). The demographics and clinical parameters of included patients were reviewed, while their recorded biochemical, hematological and conventional coagulation parameters from the collected blood samples during their admission to the hospital were analyzed. The study was approved by the Institutional Review Board of Attikon University Hospital (83;01/02/2021).

To compare the hemostatic profile of patients with COVID-19 and hip fractures with the coagulopathy associated with each of these two conditions separately, we used two previously recruited groups of patients $[8,11]$. Specifically, 198 previously recruited nonCOVID-19 patients with hip fractures represented the first comparison group showing the hemostatic profile associated with hip fractures without COVID-19 [8], while 21 previously 
recruited patients with mild COVID-19 (i.e., without need for admission to the intensive care unit due to COVID-19 related respiratory distress, similar severity to our newly enrolled patients) and without fractures represented the second comparison group showing the hemostatic profile of mild COVID-19 [11]. Patients in both these groups were on thromboprophylaxis with low molecular weight heparin (LMWH).

Descriptive statistics of the study population were calculated and presented as means \pm $\mathrm{SD}$, medians and interquartile ranges (IQR), or as frequencies (percentages) when appropriate. Demographics, clinical characteristics, conventional laboratory values and ROTEM parameters were compared between the study groups (COVID-19 patients, non-COVID-19 hip fracture patients, and COVID-19 patients with hip fractures) using the Chi-square test for categorical variables, and the Wilcoxon rank-sum (Mann-Whitney) test or the Kruskal-Wallis test for continuous variables. Multiple linear regression analysis was also performed to evaluate the independent impact of COVID-19 on the hemostatic profile of patients with hip fractures as reflected by ROTEM parameters, adjusted for age, gender, Charlson Comorbidity Index (CCI) and Body Mass Index (BMI). Stata 15.0 software was used for analysis (Stata Corp., College Station, TX, USA). For all tests, a $p$-value $<0.05$ indicates statistical significance.

\section{Results}

The final study population consisted of 20 COVID-19 patients with hip fractures, while one patient was excluded due to V Leiden disease. All patients were included in the study before surgery. All patients tested positive for COVID-19 with real-time reversetranscriptase-polymerase chain reaction (rRT-PCR) assay on admission to the hospital, while COVID-19 was considered of mild severity in all patients, and none of them needed admission to the intensive care unit due to COVID-19 related respiratory distress. The median age of the COVID-19 patients with hip fractures was 79 years (interquartile range [IQR], 72-80). There were 11 (55\%) men and $9(45 \%)$ women. COVID-19 and non-COVID-19 hip fracture patients had similar CCI $(p=0.53)$ and BMI $(p=0.61)$. Three COVID-19 patients with hip fractures presented with thromboembolic complications: two with pulmonary embolism, and one with deep vein thrombosis. The demographic and clinical parameters of the three study groups (COVID-19 patients, non-COVID-19 hip fracture patients, and COVID-19 hip fracture patients) are summarized in Table 1.

Table 1. Characteristics of the study population.

\begin{tabular}{|c|c|c|c|c|c|c|c|}
\hline & $\begin{array}{c}\text { Hip Fracture } \\
\text { Patients } \\
\text { (Group } A=198 \text { ) }\end{array}$ & $\begin{array}{l}\text { Patients with } \\
\text { Mild COVID-19 } \\
\text { (Group B = 21) }\end{array}$ & $\begin{array}{c}\text { Hip Fracture } \\
\text { Patients with } \\
\text { COVID-19 } \\
\text { (Group C }=20 \text { ) }\end{array}$ & Overall $p$ & A vs. B & A vs. C & B vs. C \\
\hline Age (years) & $\begin{array}{l}78.9 \pm 5.2 \\
80(76-82)\end{array}$ & $\begin{array}{c}68.2 \pm 20.4 \\
73.0(50.0-88.0)\end{array}$ & $\begin{array}{c}77.2 \pm 4.9 \\
79.0(72.0-80.0)\end{array}$ & 0.16 & 0.13 & 0.20 & 0.45 \\
\hline Gender (males \%) & $93(46.9)$ & $11(52.3)$ & $11(55)$ & 0.72 & 0.22 & 0.46 & 0.86 \\
\hline $\mathrm{CCI}$ & $\begin{array}{c}5.9 \pm 1.2 \\
6.0(5.0-7.0)\end{array}$ & - & $\begin{array}{c}6.1 \pm 0.9 \\
6.0(5.5-7.0)\end{array}$ & 0.53 & $\mathrm{~N} / \mathrm{A}$ & 0.53 & $\mathrm{~N} / \mathrm{A}$ \\
\hline $\mathrm{BMI}\left(\mathrm{Kg} / \mathrm{m}^{2}\right)$ & $\begin{array}{l}24.6 \pm 3.6, \\
24(22-27)\end{array}$ & - & $\begin{array}{r}24.0 \pm 2.5 \\
24.5(22-26) \\
\end{array}$ & 0.61 & $\mathrm{~N} / \mathrm{A}$ & 0.61 & $\mathrm{~N} / \mathrm{A}$ \\
\hline $\begin{array}{l}\text { Creatinine } \\
(\mathrm{mg} / \mathrm{dL})\end{array}$ & $\begin{array}{c}1.18 \pm 0.36,1.09 \\
(1.01-1.19)\end{array}$ & $\begin{array}{c}0.97 \pm 0.52 \\
0.90(0.70-1.00)\end{array}$ & $\begin{array}{c}1.29 \pm 0.21 \\
1.20(1.15-1.35)\end{array}$ & $<0.001$ & $<0.001$ & $<0.001$ & $<0.001$ \\
\hline
\end{tabular}

Data are presented as mean \pm SD; median and interquartile range. The Kruskal-Wallis test was used for the overall comparison, while the Mann-Whitney test was used for the pairwise comparisons. Abbreviations: BMI, Body Mass Index; CCI, Charlson Comorbidity Index.

COVID-19 hip fracture patients and non-COVID-19 hip fracture patients had similar platelet counts (medians: $200 \times 10^{3} / \mathrm{mL}$ vs. $219 \times 10^{3} / \mathrm{mL}, p=0.19$ ) and Prothrombin Time (medians: $12.8 \mathrm{~s}$ vs. $12.2 \mathrm{~s}, p=0.86$ ), while the activated Partial Thromboplastin Time (aPTT) was prolonged in hip fracture patients with COVID-19 (medians: $39.5 \mathrm{~s}$ vs. $31.4 \mathrm{~s}, p<0.001)$. Although prolongation of aPTT is not consistent with the procoagulant 
effect of COVID-19, the same finding has been achieved in other studies as well, where aPTT was prolonged due to COVID-19 [16,17]. Moreover, COVID-19 was associated with elevated d-dimers and fibrinogen levels since fibrinogen (medians: $4.6 \mathrm{~g} / \mathrm{L}$ vs. $3.4 \mathrm{~g} / \mathrm{L}$, $p<0.001$ ) and d-dimers (medians: $2.66 \mathrm{ng} \times 10^{3} / \mathrm{mL}$ vs. $1.85 \mathrm{ng} \times 10^{3} / \mathrm{mL}, p<0.001$ ) were higher in hip fracture patients with COVID-19 compared to hip fracture patients without COVID-19. The conventional laboratory findings of the 3 study groups (COVID-19 patients, non-COVID-19 hip fracture patients, and COVID-19 hip fracture patients) are summarized in Table 2. Additionally, the median PLT count for the three patients with thromboembolic events was $208 \times 10^{3} / \mathrm{mL}$ (IQR, 155-265), their median prothrombin time was $11.5 \mathrm{~s}$ (IQR, 10.4-12.3), their median Partial Thromboplastin Time was $37.7 \mathrm{~s}$ (IQR, 35.8-44.2), their median d-dimers level was $2.45 \mathrm{ng} \times 10^{3} / \mathrm{mL}$ (IQR, 2.18-2.74), and their median fibrinogen value was $4.4 \mathrm{~g} / \mathrm{L}$ (IQR, 4.3-5.2). Due to the small number of patients with and without thromboembolic events, comparisons of these parameters are of limited value.

Table 2. Conventional coagulation assays of the study cohort.

\begin{tabular}{|c|c|c|c|c|c|c|c|}
\hline Variables & $\begin{array}{c}\text { Hip Fracture } \\
\text { Patients } \\
\text { (Group } A=198 \text { ) }\end{array}$ & $\begin{array}{l}\text { Patients with } \\
\text { Mild COVID-19 } \\
\text { (Group B = 21) }\end{array}$ & $\begin{array}{l}\text { Hip Fracture } \\
\text { Patients with } \\
\text { COVID-19 } \\
\text { (Group C = 20) }\end{array}$ & Overall $p$ & A vs. B & A vs. $\mathrm{C}$ & B vs. C \\
\hline $\begin{array}{c}\text { PLTs } \\
\left(\text { count } \times 10^{3} / \mathrm{mL}\right)\end{array}$ & $\begin{array}{c}218.9 \pm 48.0, \\
216.0(180.0-245.0)\end{array}$ & $\begin{array}{c}285.6 \pm 120.2 \\
253.0(207.0-396.0)\end{array}$ & $\begin{array}{c}200.0 \pm 32.7 \\
201.0(189.0-211.0)\end{array}$ & $<0.001$ & 0.015 & 0.19 & 0.014 \\
\hline aPTT (s) & $\begin{array}{c}31.4 \pm 3.9 \\
31.0(29.0-34.0)\end{array}$ & $\begin{array}{c}39.2 \pm 6.7 \\
37.8(34.3-41.9)\end{array}$ & $\begin{array}{c}39.5 \pm 3.3 \\
39.5(37.0-42.4)\end{array}$ & $<0.001$ & $<0.001$ & $<0.001$ & 0.35 \\
\hline PT (s) & $\begin{array}{c}12.2 \pm 2.0 \\
12.0(11.0-14.0)\end{array}$ & $\begin{array}{c}13.5 \pm 1.9 \\
13.6(12.3-14.2)\end{array}$ & $\begin{array}{c}12.8 \pm 2.9 \\
12.1(10.8-14.7)\end{array}$ & 0.10 & 0.030 & 0.86 & 0.24 \\
\hline Fibrinogen $(\mathrm{g} / \mathrm{L})$ & $\begin{array}{c}3.4 \pm 0.5 \\
3.5(3.2-3.7)\end{array}$ & $\begin{array}{c}4.4 \pm 1.3 \\
4.3(3.9-4.9)\end{array}$ & $\begin{array}{c}4.6 \pm 0.3 \\
4.6(4.3-4.9)\end{array}$ & $<0.001$ & 0.001 & 0.001 & 0.17 \\
\hline $\begin{array}{c}\text { d-dimers } \\
\left(\mathrm{ng} \times 10^{3} / \mathrm{mL}\right)\end{array}$ & $\begin{array}{c}1.85 \pm 0.53 \\
1.85(1.50-2.17)\end{array}$ & $\begin{array}{c}1.32 \pm 1.28 \\
0.86(0.54-1.21)\end{array}$ & $\begin{array}{c}2.65 \pm 0.65 \\
2.66(2.31-3.03)\end{array}$ & $<0.001$ & $<0.001$ & $<0.001$ & $<0.001$ \\
\hline
\end{tabular}

Data are presented as mean \pm SD; median and interquartile range. The Kruskal-Wallis test was used for the overall comparison, while the Mann-Whitney test was used for the pairwise comparisons. Abbreviations: PLTs, platelets; PTT, activated partial thromboplastin time; PT, prothrombin time; INR, international normalized ratio.

Regarding the EXTEM findings, COVID-19 hip fracture patients had a higher amplitude of clot firmness at $10 \mathrm{~min}$ (medians: $70.0 \mathrm{~mm}$ vs. $54.0 \mathrm{~mm}, p<0.001$ ), maximum clot firmness (medians: $75.5 \mathrm{~mm}$ vs $65.0 \mathrm{~mm}, p<0.001$ ), alpha angle (medians: $80.0^{\circ}$ vs. $74.0^{\circ}, p<0.001$ ) and lysis index at $60 \mathrm{~min}$ (medians: $99.0 \%$ vs. $91.0 \%, p<0.001$ ) values than non-COVID-19 hip fracture patients, indicating a procoagulant activity and impaired fibrinolysis due to COVID-19 (Table 3). Interestingly, the median value of lysis index at $60 \mathrm{~min}$ (99\%) of COVID-19 patients with hip fractures was consistent with fibrinolysis shut down as defined by ROTEM parameters (EXTEM LI60 values $\geq 98 \%$ ) $[18,19]$. Moreover, COVID-19 hip fracture patients had also higher amplitude of clot firmness at $10 \mathrm{~min}$ (medians: $70.0 \mathrm{~mm}$ vs. $66.0 \mathrm{~mm}, p=0.008$ ), maximum clot firmness (medians: $75.5 \mathrm{~mm}$ vs. $72.0 \mathrm{~mm}, p=0.025$ ) and lysis index at $60 \mathrm{~min}$ (medians: $99.0 \%$ vs. $97.0 \%, p<0.001$ ) compared to COVID-19 patients without hip fractures, which also indicates that the traumatic impact of hip fractures contributes to the prothrombotic state. Furthermore, COVID-19 hip fracture patients had shorter clot formation time values compared to COVID-19 patients without hip fractures (medians: $44.0 \mathrm{~s}$ vs. $48.0 \mathrm{~s}, p<0.001$ ) and to non-COVID-19 hip fracture patients (medians: $40.0 \mathrm{~s}$ vs. $84.5 \mathrm{~s}, p<0.001$ ). Finally, clotting time was similar between COVID-19 and non-COVID-19 hip fracture patients (medians: $61.0 \mathrm{~s}$ vs. $60.0 \mathrm{~s}$, $p=0.57$ ), while COVID-19 hip fracture patients had shorter clotting time compared to COVID-19 patients without hip fractures (medians: $61.0 \mathrm{~s}$ vs. $71.0 \mathrm{~s}, p<0.001$ ). The median clotting time for the three patients with thromboembolic events was $59 \mathrm{~s}$ (IQR, 58-62), their median clot formation time was $43 \mathrm{~s}$ (IQR, 42-48), their median amplitude of clot firmness at $10 \mathrm{~min}$ was $71 \mathrm{~mm}$ (IQR, 67-72), their median maximum clot firmness was $80 \mathrm{~mm}$ (IQR, 79-85), and their median lysis index at $60 \mathrm{~min}$ was $98 \%$ (IQR, 98-99). Although these 
values indicate that patients who develop thromboembolic events have a hypercoagulable profile, statistical comparison of ROTEM parameters between patients with and without thromboembolic complications is of very limited value due to the small number of patients.

Table 3. Extrinsically activated rotational thromboelastometry test (EXTEM) parameters among the study groups.

\begin{tabular}{|c|c|c|c|c|c|c|c|}
\hline Variables & $\begin{array}{c}\text { Hip Fracture } \\
\text { Patients } \\
\text { (Group } A=198 \text { ) }\end{array}$ & $\begin{array}{l}\text { Patients with } \\
\text { Mild COVID-19 } \\
\text { (Group B = 21) }\end{array}$ & $\begin{array}{l}\text { Hip Fracture } \\
\text { Patients with } \\
\text { COVID-19 } \\
\text { (Group C = 20) }\end{array}$ & Overall $p$ & A vs. B & A vs. C & B vs. C \\
\hline EXTEM CT (s) & $\begin{array}{c}59.8 \pm 6.6 \\
60.0(56.0-64.0)\end{array}$ & $\begin{array}{c}73.5 \pm 12.0 \\
71.0(66.0-81.0)\end{array}$ & $\begin{array}{c}61.0 \pm 5.3 \\
61.0(58.0-63.5)\end{array}$ & $<0.001$ & $<0.001$ & 0.57 & $<0.001$ \\
\hline EXTEM CFT (s) & $\begin{array}{c}84.0 \pm 7.4 \\
84.5(81.0-88.0)\end{array}$ & $\begin{array}{c}59.5 \pm 24.9 \\
48.0(45.0-61.0)\end{array}$ & $\begin{array}{c}44.4 \pm 4.2 \\
44.0(41.0-47.0)\end{array}$ & $<0.001$ & $<0.001$ & $<0.001$ & 0.019 \\
\hline EXTEM A10 (mm) & $\begin{array}{c}53.4 \pm 4.6 \\
54.0(51.0-57.0)\end{array}$ & $\begin{array}{c}65.0 \pm 5.4 \\
66.0(63.0-69.0)\end{array}$ & $\begin{array}{c}69.3 \pm 5.9 \\
70.0(67.0-72.5)\end{array}$ & $<0.001$ & $<0.001$ & $<0.001$ & 0.008 \\
\hline EXTEM MCF (mm) & $\begin{array}{c}65.8 \pm 5.6 \\
65.0(63.0-69.0)\end{array}$ & $\begin{array}{c}72.4 \pm 4.0 \\
72.0(70.0-74.0)\end{array}$ & $\begin{array}{c}75.9 \pm 5.1 \\
75.5(72.5-79.5)\end{array}$ & $<0.0001$ & $<0.001$ & $<0.001$ & 0.025 \\
\hline $\begin{array}{l}\text { EXTEM Alpha } \\
\text { angle }\left(^{\circ}\right)\end{array}$ & $\begin{array}{c}73.7 \pm 4.8 \\
74.0(71.0-77.0)\end{array}$ & $\begin{array}{c}78.1 \pm 4.7 \\
80.0(78.0-81.0 .)\end{array}$ & $\begin{array}{c}80.0 \pm 5.2 \\
80.0(76.0-84.0 .)\end{array}$ & $<0.001$ & $<0.001$ & $<0.001$ & 0.43 \\
\hline EXTEM LI60 (\%) & $\begin{array}{c}91.6 \pm 5.4 \\
91.0(88.0-95.0)\end{array}$ & $\begin{array}{c}96.3 \pm 2.9 \\
97.0(94.0-99.0)\end{array}$ & $\begin{array}{c}98.5 \pm 1.2 \\
99.0(98.0-99.5)\end{array}$ & $<0.001$ & $<0.001$ & $<0.001$ & 0.011 \\
\hline
\end{tabular}

Data are presented as mean \pm SD; median and interquartile range. The Kruskal-Wallis test was used for the overall comparison, while the Mann-Whitney test was used for the pairwise comparisons. Abbreviations: CT, clotting time; CFT, clot formation time; A10, clot amplitude at $10 \mathrm{~min}$; MCF, maximum clot firmness; LI60, lysis index at $60 \mathrm{~min}$.

Multivariable linear regression analysis (adjusted for gender, age, BMI, and CCI index) demonstrated that COVID-19 was independently associated with increased amplitude of clot firmness at 10 min (coefficient: 15.8, 95\% CI: 13.6-18.1; $p<0.001$ ), maximum clot firmness (coefficient: 10.0,95\% CI: 7.4-12.5; $p<0.001$ ), lysis index at 60 min (coefficient: 6.8, 95\% CI: 4.3-9.3; $p<0.001$ ) and alpha angle (coefficient: 6.1, 95\% CI: 3.9-8.4; $p<0.001$ ) in hip fracture patients, while COVID-19 significantly shortened clot formation time (coefficient: $-39.9,95 \% \mathrm{CI}:-43.4$ to $-36.6 ; p<0.001)$. The results of regression analysis further confirmed the direct relationship of COVID-19 with hypercoagulability and fibrinolysis shutdown in patients with hip fractures (Table 4).

Table 4. Results of multivariable regression analysis for the evaluation of the effect of COVID on the coagulation profile of patients with hip fractures as evaluated by ROTEM parameters, adjusted for age, gender, Charlson Comorbidity Index and Body Mass Index. In the model, presence of COVID-19 disease is used as an independent variable and ROTEM parameters as dependent variables.

\begin{tabular}{cccc}
\hline ROTEM Parameters & \multicolumn{2}{c}{ Presence of COVID-19 in Patients with Hip Fracture } \\
\hline & Coefficient & $\mathbf{9 5 \%}$ CI & $p$-Value \\
\hline EXTEM CFT $(\mathrm{s})$ & -39.9 & -43.3 to -36.6 & $<0.001$ \\
\hline EXTEM MCF $(\mathrm{mm})$ & 10.0 & $7.4-12.5$ & $<0.001$ \\
\hline EXTEM A10 $(\mathrm{mm})$ & 15.8 & $13.6-18.1$ & $<0.001$ \\
\hline EXTEM LI60 $(\%)$ & 6.8 & $4.3-9.3$ & $<0.001$ \\
\hline EXTEM alpha angle $\left({ }^{\circ}\right)$ & 6.1 & $3.9-8.4$ & $<0.001$ \\
\hline
\end{tabular}

Abbreviations: CI, confidence interval, CT, clotting time; CFT, clot formation time; A10, clot amplitude at 10 min; MCF, maximum clot firmness; LI60, lysis index at $60 \mathrm{~min}$.

\section{Discussion}

The impact of COVID-19 on the prognosis of patients with hip fractures has been evaluated in a few studies indicating that COVID-19 in hip fracture patients is associated with a seven- to 10-fold increased mortality risk [5,20-22]. The also markedly increased complication rate contributes to the low survival of these patients. The reported incidence 
of thromboembolic complications in COVID-19 positive patients with hip fractures under thromboprophylaxis is $6.5-13.5 \%$, while the respective incidence after hip fractures without COVID-19 is only about $1.5-2.0 \%$ [23-26]. Our results are in line with these findings since the rate of thromboembolic events in our study was also $15 \%$ (3 of 20 patients). Based on the results of our study, the significantly higher thrombotic risk in COVID-19 patients with hip fractures can be attributed to the increased clot strength and fibrinolysis shutdown, as shown by ROTEM findings. More specifically, COVID-19 was independently associated with increased amplitude of clot firmness at $10 \mathrm{~min}$, maximum clot firmness, lysis index at $60 \mathrm{~min}$ and alpha angle in hip fracture patients, while COVID-19 significantly shortened clot formation time. The increased thromboembolic risk due to COVID-19 highlights the importance of changes in the thromboprophylactic protocol of these patients, therefore further clinical research is warranted to ascertain the need for modification of the current thromboprophylactic protocol, including individualized anticoagulation based on ROTEM findings, increase in the anticoagulation dose or administration of fibrinolytic agents.

COVID-19 resulted in enhanced clot strength and firmness as shown by the higher A10 and MCF parameters in COVID-19 patients with hip fractures. The same effect of COVID-19 on clot dynamics has been also demonstrated in other studies using viscoelastic methods to investigate the nature of hemostatic disturbances due to COVID-19 associated coagulopathy $[27,28]$. In a recent systematic review reporting the outcomes of five studies with TEG results and five studies with ROTEM results in COVID-19 patients, increased clot strength was apparent in all TEG studies as shown by the increased maximum amplitude, a thromboelastographic parameter that reflects enhanced clot strength. In 4 out of the 5 ROTEM studies, high MCF values were also reported. A possible cause for the increased clot strength due to COVID-19 is increased thrombin generation due to endothelial damage, as shown by the elevated endogenous thrombin potential (ETP) in COVID-19 patients $[28,29]$. Increased clot strength resulting in a hypercoagulable state has been also demonstrated in patients with hip fractures [14]. The combining effect of COVID-19 associated coagulopathy and hip fracture coagulopathy on clot firmness may be one of the major causes for increased thromboembolic incidence in this population [8,30,31]. Although CFT was shortened in our COVID-19 patients with hip fractures, indicating an accelerated clot formation dynamic due to COVID-19, CT was similar between COVID-19 and non-COVID-19 patients. A similar finding was highlighted by another systematic review that investigated the role of TEG analysis in COVID-19 patients, with most of the included studies reporting a normal R-time, a TEG parameter similar to CT that corresponds to the induction of coagulation, showing that this parameter is less consistent to reveal hypercoagulability in this clinical setting [32].

Another important finding regarding the effect of COVID-19 on the hemostatic mechanisms of patients with hip fractures was fibrinolysis shutdown. Impaired fibrinolysis has been also identified as a significant cause for increased thromboembolic risk in COVID-19 patients in other studies $[9,10]$. Elevated plasminogen activator inhibitor-1 (PAI-1) activity has been hypothesized as one of the major causes for COVID-19 associated fibrinolysis resistance and fibrinolysis shutdown in COVID-19 patients [29]. In a single-center cohort study of 40 critically ill patients with COVID-19, Kruse et al. also found signs of severe hypofibrinolysis using ROTEM analysis. The authors of this study reported that maximum lysis (ML), a ROTEM parameter for the evaluation of fibrinolysis similar to LI60, was lower in patients with thromboembolic events compared to patients without thromboembolic events [9]. Moreover, they showed that combining values of ROTEM parameters for hypofibrinolysis with elevated D-dimer levels had a high prediction accuracy for thromboembolic complications. A similar finding was also shown by Wright et al., who studied the hemostatic profile of 44 critically-ill COVID-19 patients using TEG and found a complete fibrinolysis shutdown in $57 \%$ of their patients, while low LY30, a parameter similar to LI60 was associated with thromboembolic events [10]. The incidence of complete shutdown in our study cohort was $80 \%$ (16 of 20 patients), higher than that 
reported by Wright et al. which can be attributed to the combining effect of hip fractures and COVID-19.

There are some limitations of our study that must be acknowledged. First, the relatively small number of patients does not allow us to draw any firm conclusions regarding the clinical implications of the identified hypercoagulability due to COVID-19, since comparisons of patients with and without VTE events would provide results of very limited strength. However, although this is a pilot study with a small number of patients, our findings are in line with similar findings of other studies regarding the prothrombotic state of COVID-19. Additionally, due to the use of two previously recruited groups, the three analyzed groups in this study were not matched for certain demographic and clinical parameters. However, logistic regression was performed to address the issue of potential confounding factors of the relationship between COVID-19 and ROTEM findings in hip fracture patients. Information about the mortality or complication rate of the studied population is also limited by the short follow up of the study, since it is possible that a larger number of patients than the one reported presented with thromboembolic complications in the following weeks. Also, hospital records for some clinical parameters (e.g., comorbidities, medications) and laboratory assays (inflammatory markers, INTEM and APTEM assays) for the included patients were limited, which did not allow any comparison of these parameters among the three studied groups. Last, other laboratory studies of coagulation to confirm and further investigate the identified mechanisms responsible for the hypercoagulability seen in our study group were not performed. Specifically, plasminogen activator inhibitor-1 (PAI-1) activity and endogenous thrombin potential (ETP) were not determined, two laboratory variables that could further elucidate the pathophysiology of the observed fibrinolysis shutdown and enhanced clot firmness, respectively.

\section{Conclusions}

Conclusively, COVID-19 has a detrimental impact on the already increased thrombotic risk of patients with hip fractures, as shown by the high reported rate of thromboembolic complications in this population, which was also evident in our study. Our study shed light on the pathophysiology involved in the hypercoagulability associated with the increased thrombotic risk of these patients. The main causes for the coagulopathy associated with a higher thrombotic risk in COVID-19 patients with hip fractures include increased clot strength and fibrinolysis shutdown as shown by the altered ROTEM findings. These hemostatic alterations cannot be detected by conventional coagulation studies, while elevated fibrinogen levels cannot reliably detect the hemostatic profile associated with thromboembolic events.

Author Contributions: A.G.T. and A.E.T. conceptualized the project. A.G.T., D.V.P., I.G.T., A.E.T. and S.B. designed the methodology. K.A.T., A.F.M., P.K., A.G.V., D.P., G.K.N., S.G. and P.J.P. were involved in data collection, analysis, and interpretation. A.G.T., D.P. and D.V.P. wrote the manuscript. All the co-authors critically revised and finally approved the manuscript. All authors agree to be held accountable for all aspects of the work in ensuring that questions related to the accuracy or integrity of any part of the work are appropriately investigated and resolved. All authors have read and agreed to the published version of the manuscript.

Funding: This research received no external funding.

Institutional Review Board Statement: The study was conducted according to the guidelines of the Declaration of Helsinki, and approved by the Institutional Review Board (IRB) of Attiko Hospital (ref. number: 83; 01/02/2021).

Informed Consent Statement: Informed consent was obtained from all subjects involved in the study.

Data Availability Statement: The data presented in this study are available upon reasonable request to the corresponding authors.

Conflicts of Interest: The authors declare no conflict of interest. 


\section{References}

1. Jenkins, P. The Early Effect of COVID-19 on Trauma and Elective Orthopaedic Surgery. British Orthopaedic Association (BOA), 2020. Available online: https://www.boa.ac.uk/resources/knowledge-hub/the-early-effect-of-covid-19-on-trauma-andelective-orthopaedic-surgery.html (accessed on 7 July 2021).

2. Oussedik, S.; Zagra, L.; Shin, G.Y.; D'Apolito, R.; Haddad, F.S. Reinstating Elective Orthopaedic Surgery in the Age of COVID-19. Bone Jt. J. 2020, 102, 807-810. [CrossRef]

3. Nuñez, J.H.; Sallent, A.; Lakhani, K.; Guerra-Farfan, E.; Vidal, N.; Ekhtiari, S.; Minguell, J. Impact of the COVID-19 Pandemic on an Emergency Traumatology Service: Experience at a Tertiary Trauma Centre in Spain. Injury 2020, 51, 1414-1418. [CrossRef]

4. Scott, C.E.; Holland, G.; Powell-Bowns, M.F.; Brennan, C.M.; Gillespie, M.; Mackenzie, S.P.; Clement, N.D.; Amin, A.K.; White, T.O.; Duckworth, A.D. Population mobility and adult orthopaedic trauma services during the COVID-19 pandemic: Fragility fracture provision remains a priority. Bone Jt. Open 2020, 1, 182-189. [CrossRef]

5. Vives, J.M.; Jornet-Gibert, M.; Cámara-Cabrera, J.; Esteban, P.L.; Brunet, L.; Delgado-Flores, L.; Camacho-Carrasco, P.; Torner, P.; Marcano-Fernández, F.; Group, S.H. Mortality Rates of Patients with Proximal Femoral Fracture in a Worldwide Pandemic: Preliminary Results of the Spanish HIP-COVID Observational Study. J. Bone Jt. Surg. Am. 2020, 102, e69. [CrossRef]

6. Falck-Ytter, Y.; Francis, C.W.; Johanson, N.A.; Curley, C.; Dahl, O.E.; Schulman, S.; Ortel, T.L.; Pauker, S.G.; Colwell, C.W., Jr. Prevention of VTE in orthopedic surgery patients: Antithrombotic therapy and prevention of thrombosis: American College of Chest Physicians evidence-based clinical practice guidelines. Chest 2012, 141, e278S-e325S. [CrossRef]

7. Cap, A.; Hunt, B. Acute traumatic coagulopathy. Curr. Opin. Crit. Care 2014, 20, 638-645. [CrossRef] [PubMed]

8. Tsantes, A.G.; Trikoupis, I.G.; Papadopoulos, D.V.; Tsante, K.A.; Mavrogenis, A.F.; Koulouvaris, P.; Savvidou, O.D.; Kontogeorgakos, V.A.; Piovani, D.; Kriebardis, A.G.; et al. Higher coagulation activity in hip fracture patients: A case-control study using rotational thromboelastometry. Int. J. Lab. Hematol. 2020, 43, 477-484. [CrossRef]

9. Kruse, J.M.; Magomedov, A.; Kurreck, A.; Münch, F.H.; Koerner, R.; Kamhieh-Milz, J.; Kahl, A.; Gotthardt, I.; Piper, S.K.; Eckardt, K.U.; et al. Thromboembolic complications in critically ill COVID-19 patients are associated with impaired fibrinolysis. Crit. Care 2020, 24, 676. [CrossRef] [PubMed]

10. Wright, F.L.; Vogler, T.O.; Moore, E.E.; Moore, H.B.; Wohlauer, M.V.; Urban, S.; Nydam, T.L.; Moore, P.K.; McIntyre, R.C., Jr. Fibrinolysis Shutdown Correlation with Thromboembolic Events in Severe COVID-19 Infection. J. Am. Coll. Surg. 2020, 231, 193-203.e1. [CrossRef]

11. Tsantes, A.E.; Frantzeskaki, F.; Tsantes, A.G.; Rapti, E.; Rizos, M.; Kokoris, S.I.; Paramythiotou, E.; Katsadiotis, G.; Karali, V.; Flevari, A.; et al. The haemostatic profile in critically ill COVID-19 patients receiving therapeutic anticoagulant therapy. Medicine 2020, 99, 23365. [CrossRef] [PubMed]

12. Tsantes, A.E.; Tsantes, A.G.; Kokoris, S.I.; Bonovas, S.; Frantzeskaki, F.; Tsangaris, I.; Kopterides, P. COVID-19 Infection-Related Coagulopathy and Viscoelastic Methods: A Paradigm for Their Clinical Utility in Critical Illness. Diagnostics 2020, $10,817$. [CrossRef]

13. Hincker, A.; Feit, J.; Sladen, R.; Wagener, G. Rotational thromboelastometry predicts thromboembolic complications after major non-cardiac surgery. Crit. Care 2014, 18, 549. [CrossRef]

14. Tsantes, A.G.; Papadopoulos, D.V.; Trikoupis, I.G.; Tsante, K.A.; Mavrogenis, A.F.; Koulouvaris, P.; Piovani, D.; Kriebardis, A.G.; Gialeraki, A.; Nikolopoulos, G.K.; et al. Rotational Thromboelastometry Findings Are Associated with Symptomatic Venous Thromboembolic Complications after Hip Fracture Surgery. Clin. Orthop. Relat. Res. 2021. [CrossRef] [PubMed]

15. Sokou, R.; Piovani, D.; Konstantinidi, A.; Tsantes, A.G.; Parastatidou, S.; Lampridou, M.; Ioakeimidis, G.; Gounaris, A.; Iacovidou, N.; Kriebardis, A.G.; et al. A Risk Score for Predicting the Incidence of Hemorrhage in Critically Ill Neonates: Development and Validation Study. Thromb. Haemost. 2020, 121, 131-139. [CrossRef] [PubMed]

16. Quintana-Díaz, M.; Andrés-Esteban, E.M.; Ramírez-Cervantes, K.L.; Olivan-Blázquez, B.; Juárez-Vela, R.; Gea-Caballero, V. Coagulation Parameters: An Efficient Measure for Predicting the Prognosis and Clinical Management of Patients with COVID-19. J. Clin. Med. 2020, 9, 3482. [CrossRef]

17. Luo, H.C.; You, C.Y.; Lu, S.W.; Fu, Y.Q. Characteristics of coagulation alteration in patients with COVID-19. Ann. Hematol. 2020, 100, 45-52. [CrossRef] [PubMed]

18. Lampridou, M.; Sokou, R.; Tsantes, A.G.; Theodoraki, M.; Konstantinidi, A.; Ioakeimidis, G.; Bonovas, S.; Politou, M.; Valsami, S.; Iliodromiti, Z.; et al. ROTEM diagnostic capacity for measuring fibrinolysis in neonatal sepsis. Thromb. Res. 2020, 192, 103-108. [CrossRef]

19. Stettler, G.R.; Moore, E.E.; Moore, H.B.; Nunns, G.R.; Silliman, C.C.; Banerjee, A.; Sauaia, A. Redefining postinjury fibrinolysis phenotypes using two viscoelastic assays. J. Trauma Acute Care Surg. 2019, 86, 679-685. [CrossRef]

20. Hall, A.J.; Clement, N.D.; Farrow, L.; MacLullich, A.M.J.; Dall, G.F.; Scott, C.E.H.; Jenkins, P.J.; White, T.O.; Duckworth, A.D. IMPACT-Scot report on COVID-19 and hip fractures. Bone Jt. J. 2020, 102, 1219-1228. [CrossRef] [PubMed]

21. Clement, N.D.; Ng, N.; Simpson, C.J.; Patton, R.F.L.; Hall, A.J.; Simpson, A.H.R.W.; Duckworth, A.D. The prevalence, mortality, and associated risk factors for developing COVID-19 in hip fracture patients: A systematic review and meta-analysis. Bone Jt. Res. 2020, 9, 873-883. [CrossRef] [PubMed]

22. Zhong, H.; Poeran, J.; Liu, J.; Wilson, L.; Memtsoudis, S. Hip fracture characteristics and outcomes during COVID-19: A large retrospective national database review. Br. J. Anaesth. 2021, 127, 15-22. [CrossRef] 
23. Slullitel, P.; Lucero, C.; Soruco, M.; Barla, J.D.; Benchimol, J.A.; Boietti, B.R. Prolonged social lockdown during COVID-19 pandemic and hip fracture epidemiology. Int. Orthop. 2020, 44, 1887-1895. [CrossRef]

24. Egol, K.; Konda, S.; Bird, M.L.; Dedhia, N.; Landes, E.K.; Ranson, R.A.; Solasz, S.J.; Aggarwal, V.; Bosco, J.; Furgiuele, D.L.; et al. Increased Mortality and Major Complications in Hip Fracture Care During the COVID-19 Pandemic: A New York City Perspective. J. Orthop. Trauma 2020, 34, 395-402. [CrossRef] [PubMed]

25. Kayani, B.; Onochie, E.; Patil, V.; Begum, F.; Cuthbert, R.; Ferguson, D.; Bhamra, J.S.; Sharma, A.; Bates, P.; Haddad, F.S. The effects of COVID-19 on perioperative morbidity and mortality in patients with hip fractures. Bone Jt. J. 2020, 102, 1136-1145. [CrossRef] [PubMed]

26. McNamara, I.; Sharma, A.; Prevost, T.; Parker, M. Symptomatic venous thromboembolism following a hip fracture. Acta Orthop. 2009, 80, 687-692. [CrossRef] [PubMed]

27. Słomka, A.; Kowalewski, M.; Żekanowska, E. Hemostasis in Coronavirus Disease 2019—Lesson from Viscoelastic Methods: A Systematic Review. Thromb. Haemost. 2021. [CrossRef]

28. Schneider, T.; Siegemund, T.; Siegemund, R.; Petros, S. Thrombin generation and rotational thromboelastometry in the healthy adult population. Hämostaseologie 2015, 35, 181-186. [CrossRef] [PubMed]

29. Nougier, C.; Benoit, R.; Simon, M.; Desmurs-Clavel, H.; Marcotte, G.; Argaud, L.; David, J.S.; Bonnet, A.; Negrier, C.; Dargaud, Y. Hypofibrinolytic state and high thrombin generation may play a major role in SARS-COV2 associated thrombosis. J. Thromb. Haemost. 2020, 18, 2215-2219. [CrossRef] [PubMed]

30. Liu, C.; Guan, Z.; Xu, Q.; Zhao, L.; Song, Y.; Wang, H. Relation of thromboelastography parameters to conventional coagulation tests used to evaluate the hypercoagulable state of aged fracture patients. Medicine 2016, 95, 3934. [CrossRef] [PubMed]

31. Wilson, D.; Cooke, E.A.; McNally, M.A.; Wilson, H.K.; Yeates, A.; Mollan, R.A. Changes in coagulability as measured by thrombelastography following surgery for proximal femoral fracture. Injury 2001, 32, 765-770. [CrossRef]

32. Hartmann, J.; Ergang, A.; Mason, D.; Dias, J. The Role of TEG Analysis in Patients with COVID-19-Associated Coagulopathy: A Systematic Review. Diagnostics 2021, 11, 172. [CrossRef] [PubMed] 